\title{
Health inequalities in the UK: remedy requires action beyond redistribution of wealth
}

When the Labour government came to power in 1997, one of its stated aims was to reduce health inequalities in the UK. With this in mind it commissioned Sir Donald Acheson to produce a report on the matter which, unsurprisingly, indicated that health inequalities were strongly related to wealth inequalities, and that social and economic policy was a greater determinant of this than healthcare policy. ${ }^{1}$

Now over 10 years on, the matter has been revisited, with the Department of Health publishing a progress report. ${ }^{2}$ It is an excellent document, but sadly short on evidence of tangible improvement in several areas. In a post-publication speech to the Fabian Society, ${ }^{3}$ the then Health Secretary Alan Johnson tried to make political capital, stating that under the Conservatives mortality rates between men in the highest and lowest socioeconomic groups had widened. This is true; however, what he failed to acknowledge is that his own government has had a dozen years to close the gap, and has not done so. In short, this is because the government's economic policy has been targeted at helping the very rich, while attempting to help the poor through redistribution of wealth, chiefly on a regional basis. In this essay, I shall argue that this strategy is flawed, has failed to address the underlying reasons for poverty, and placed an unsustainable pressure on middle-income earners, not least healthcare workers.

Peter Mandelson famously stated that 'New Labour is intensely relaxed about people getting filthy rich', while Tony Blair, ever the populist, stated that limiting the earning power of Premiership footballers was not in his job description. In the early months of the government, it was perhaps necessary to reassure the money markets that Labour was not anti-business. Indeed, its economic policy has favoured the rich. The huge wages of show business and sports stars are common knowledge, but with such A-listers in the low thousands at most, their numbers are too small to affect the wider economy. By contrast, the financial sector is a sizeable employer, and has been the main driver of the economy, benefiting from deregulation for many years, and then ironically being bailed out by taxpayers' money when its risk-taking culture led to the current financial crisis. ${ }^{4} \mathrm{~A}$ striking consequence of this has been the increase in regional disparities in wealth, which have grown steadily during this period. The financial sector's hub is the City of London, and in the wealthiest parts of London favoured by financial workers, the mean household income is 4.5 times the national average. ${ }^{3}$ By contrast, post-industrial cities and towns, predominantly in the North, Scotland, and Wales, have significant deprivation: the mean income in Anglesey is just $54 \%$ of the average. ${ }^{3}$ It is in these regions where the Labour government has tried to assist its traditional support by ameliorating the damage through generous public spending. The health consequences of this divide are stark. In Kensington, the country's wealthiest area, the male life expectancy is 83 years. ${ }^{2}$ By contrast, the Glasgow region harbours nine areas with the worst health outcomes, ${ }^{5}$ with a male life expectancy of 69 years for the whole city, ${ }^{6}$ and just 53 years for Calton -10 years less than the average for India. ${ }^{6}$

In daily life, nothing much appears to change in Britain, although, as I shall argue later, this should not breed complacency. In AN Wilson's excellent book A Short History of London, he notes that leisure, rather than work, appears dominant in the capital's wealthiest areas. ${ }^{7}$ In Kensington and Knightsbridge, in Chelsea and Fulham, in Hampstead and St John's Wood, and in Richmond and Wimbledon, the wives, daughters and girlfriends of rich men shop and lunch, oblivious to the recession or to the constraints of the working day. Further afield in the commuter towns of the Home
Counties, the womenfolk are no less materialistic, but if anything, even more predictable in their aspirations, dress and manner than their metropolitan sisters. Never in the history of female conflict have so many fought so hard for the dubious privilege of looking exactly the same as each other, as a cohort of Home Counties housewives.

Meanwhile, in inner cities and on sink estates, people are also not working, but for quite different reasons; indeed in some areas, one-parent poverty is the norm, and a second generation that may never work is well into adult life. Cruelly mocked as an 'underclass' by the press, many are in fact victims of a combination of circumstances. The decline of manufacturing decimated many traditional jobs and communities based around them, while a poor educational system failed to prepare subsequent generations for change. Low-skilled service industry jobs might have provided gainful employment, but this sector is dominated by immigrants. One could argue that it is a partial success that health inequalities have not worsened when you consider the widening income gap between the rich and poor, and tax credits, child poverty programmes, and continued access to free healthcare have indeed helped. However, the problem of social exclusion remains as rife, and social mobility has all but stalled. ${ }^{8}$ Furthermore, the poorest regions are likely to be most affected by the recession, since they are the most dependent on tax revenues which will diminish.

A simple explanation of a redistributive strategy is that it takes from the rich to help out the poor; however, the actual situation as applied by the government is subtly different from true Robin Hood economics. The very rich, in practice the top $2 \%$ of earners, have enjoyed many tax breaks, leaving upper-middle and middleincome earners shouldering a disproportionate burden. ${ }^{8}$ Perversely, 
Britain is a high-tax country for its own citizens while being a tax haven for wealthy exiles, a situation quite different to that of, say, Monaco, Switzerland, or Dubai. Had small and mid-sized businesses received as much help, prosperity could have been more evenly spread and more sustainable; however, these struggle, weighed down by bureaucracy and high running costs. We need look no further than our own surgeries as an example. Many colleagues are still working from cramped, shabby premises that were not fit for purpose in 1959, let alone 2009, particularly in deprived communities which the government purports to care about. The $£ 8$ million squandered on the populist nonsense of the patient access survey ${ }^{9}$ could have been better spent on upgrading premises, and thus improving the patient experience. GPC leader Laurence Buckman is rightly incensed about this, noting that it is but a ploy to deprive practices of income. ${ }^{9}$

Perverse funding also discriminates against GPs in affluent areas, who face higher staff and running costs. My Hertfordshire practice is located in such an area which, nevertheless, generates a significant demand on health resources by dint of chronic disease in its older population, ${ }^{10}$ as well as the social fragmentation found in populations made up of diverse incomers from other areas. ${ }^{11}$ Although deprivation payments (which, quite reasonably, we never received) were abolished under the GMS2 contract, ${ }^{12}$ this has been replaced by the far less transparent 'weighted' list size, something as surreptitious as any stealth tax. Our actual list size of 6200 thus becomes 5650 for no other reason than being in an area of affluence. Not only is this a hit on personal income, but it put paid to any investment in further nursing resource, which would have been welcome in this area.

Despite the redistributive strategy, the
UK continues to be a sharply polarised country, and this has a negative effect on social cohesion that will certainly worsen if, as expected, the overall economy continues to do so. The social and health problems of the poorest sections in our population are obvious; however, it is also at the top that an undesirable social apartheid has occurred. A generation ago the wealthy areas mentioned before were also home to the very rich, but were not an exclusion zone for middle class professionals. They are now; for no nurse, teacher, university academic, vicar, or rabbi can afford to live there, nor indeed can any doctor or dentist unless possessing a substantial private practice. Wealthy ghettos are effectively created, housing one or two occupational groups. Furthermore, a pervasive culture of avarice has been created, and is now recognised as a source of anxiety and stress. ${ }^{13-15}$ The effects on the next generation are most worrying.

The negative effect of this, and other unwelcome societal trends, profoundly affects our children and young people. UNICEF has recently published a report on the wellbeing of children in developed countries, using a wide range of criteria to assess physical and emotional wellbeing, the accent being on wellness rather than illness, though the latter also features..$^{16}$ It is an excellent report, but for the humanists among us, again makes grim reading. Children in the UK and the US the countries which put the greatest emphasis on acquiring personal wealth to an evangelical degree - are consistently shown to be the least happy in this league table. ${ }^{16}$ By contrast, those from countries with more even income distributions, such as the Netherlands and the Scandinavian countries, tend to score best. ${ }^{16}$ The UK has a high percentage of children living in relative poverty, but arguably the most distressing statistic is having the highest percentage living in lone parent households. Lone parenthood is still championed as a triumph of personal choice by some on the liberal left; however, there is nothing romantic about the reality into which many children are born, all too often the result of transient, often violent relationships, leading their mothers to one real choice only - lifelong poverty and dependency. Rebellion by unhappy children is a predictable menu: smoking, binge drinking, drug misuse, and underage sex, all with obvious deleterious effects on physical and psychological health, and often repeating the sorry cycle of their parents. If all does not go well at home, and even if it does, good outside role models are invaluable, and the lack of such role models for young men from disadvantaged backgrounds, and particularly for young black men, is recognised. ${ }^{17}$ However, just as that appears to be improving (think Barack Obama and Lewis Hamilton), real concern is being expressed about the influence of glamour models and reality TV starlets on girls and young women across the whole socioeconomic spectrum. ${ }^{18}$ Inarticulate, indulgent, vacuous, and sexually incontinent, they are an awful influence, but one must also acknowledge the paucity of serious competition in public life. For example, how many of the 'Blair Babes' of 1997 - the name itself was an infantilisation - have fashioned stellar political careers and turned out to be inspiring people?

I believe that there is a general disappointment with the current government's social and health policy, far beyond what is often dismissed as envy. The most disadvantaged sections of the population have had more public money spent, but this has not addressed the educational and employment issues, nor the social dynamics which keep them ensnared in the dependency culture. Scotland and Wales have received above average spending per capita, an obvious example being that these regions (and Northern Ireland) now have free 
prescriptions for all. Despite this, the nationalist movements there have gathered pace. Once simplistically antiEnglish, they now assume a more erudite discourse, not least because leaders in these regions realise they cannot build a long-term future from redistribution from Middle England, from which there are no more pips left to squeeze. Indeed, one weakness in macro-economic models is that they do not account for the considerable variation in prosperity within regions, which may be labelled nominally affluent or deprived. London, for example, has considerable deprivation, particularly in its Southern and Eastern boroughs. Bermondsey is one such area and has predictably poor health outcomes. ${ }^{5}$ It is just four stops on the Jubilee Line from Westminster, but might as well be on another planet. Conversely, I trust that there are Old Firm footballers in Glasgow and landed gentry in Perthshire and Snowdonia who question the fairness of their free prescriptions, while nurses and lab technicians in England pay for theirs.

Middle-class professionals in affluent regions must constitute, in historical terms, the least rebellious creatures imaginable. However, this group, which includes most healthcare workers, is getting restive and can justifiably claim to have the worst of all worlds, having in the last decade seen stagnation of personal income and had to contend with a tripling of housing costs and higher taxes, while receiving neither City bonuses nor benefiting from the largesse in public funding diverted to poorer regions.

Prohibitive housing costs are condemning many people, including graduates, to live with their parents through their 30s and even beyond, which is hardly conducive to personal wellbeing. Indeed, property ownership (or not) appears to have become something of a fault line within the middle classes. The British public, famed for its stoical resignation, may just have had enough of the fundamental dishonesty that is the cabal of pop politics, political correctness, soundbites and spin which insults the intelligence of the majority but has, unfortunately, penetrated our institutions. Enough of eulogising 'choice' we don't have and 'change' we don't need. Enough of the smarmy MP who praises the 'vibrant multiculturalism' of a failing comprehensive school, to which he would never dream of sending his own children, for they are safely in Eton, Harrow, or Winchester.

It is clear that there are limits to what medicine can achieve in redressing health inequalities. As good professionals we will continue to do our best in the consulting room on an individual level, but cannot out-muscle the effects of economic policy. In that vein, medical institutions, including the Royal Colleges, may make themselves more useful by trying to exert political influence. Old-style socialism is a failed experiment for whose return there is no clamour. Nevertheless, the current policies of favouring the very rich, who have far more than they need to be comfortable or happy, and papering over the cracks of the poor by public money, is unfair and unsustainable. It has also alienated the professional middle class, something that is unlikely to be forgiven at the ballot box and should be a lesson for any future government, irrespective of which party forms it.

\section{Edin Lakasing}

\section{REFERENCES}

1. Acheson D. Independent enquiry into inequalities of health. London: HMSO, 1998.

2. Department of Health. Tackling health inequalities: 10 years on. London: HMSO, 2009.

http://www.dh.gov.uk/en/Publicationsandstatistics/Public ations/PublicationsPolicyAndGuidance/DH 098936 (accessed 7 Sep 2009).

3. Hawkes N. Mind the gap. Britain is a profoundly unequal country, and there's not much that health care can do about that. BMJ 2009; 338: b2604, doi: 10.1136/bmj.b2604.

4. Cable V. The Storm: the world economic crisis and what it means. London: Atlantic Books, 2009.

5. Davey-Smith G, Dorling D, Shaw M. Poverty, inequality and health in Britain: 1800-2000: a reader. Bristol: Policy Press, 2001

6. Eurotopics. The Spectator - United Kingdom. Glasgow's low life expectancy. February 9, 2006.

http://www.eurotopics.net/en/archiv/archiv_results/archiv _article/ARTICLE2513-Glasgow-s-low-life-expectancy (accessed 7 Sep 2009).

7. Wilson AN. London: a short history. Weidenfeld and Nicolson: London, 2004

8. Walden G. Time to emigrate? London: Gibson Square Books Ltd, 2006

9. Management in Practice. 'Flawed and unfair' patient access survey will hit practices, BMA warns. 1 June 2009. http://www.managementinpractice.com/default.asp?page $=$ article.display\&title $=\% 22$ Flawedandunfair $\% 22$ patientac cesssurveywillhitpractices\%2CBMAwarns\&article.id=168 57 (accessed 7 Sep 2009).

10. Lakasing E, Mahaffey W. A practice-based survey of mortality patterns and terminal care provision. $\mathrm{Br} \mathrm{J}$ Community Nurs 2005; 10(8): 378-380.

11. Lakasing E. Deprivation and primary care: a time to revisit. Br J Gen Pract 2006; 56: 636-637.

12. Department of Health. Investing in general practice: the new general medical services contract. London: $\mathrm{DoH}$, 2003.

13. Heath I. Excessive wealth is damaging the nation's health BMJ 2009; 338: b1293, doi: 10.1136/bmj.b1293

14. Hamilton C. Growth fetish. Crow's Nest: Allen \& Unwin, 2003.

15. James O. Affluenza: how to be successful and stay sane. London: Vermilion, 2007.

16. UNICEF. Child poverty in perspective: An overview of child well-being in rich countries. Innocenti Report Card 7, 2007. UNICEF Innocenti Research Centre, Florence, 2007. http://www.unicef-

irc.org/publications/pdf/rc7_eng.pdf (accessed 7 Sep 2009).

17. Womack S. Black boys 'need role models not rappers' Telegraph 2007; 10 Aug: http://www.telegraph.co.uk/news/uknews/1559904/Black -boys-need-role-models-not-rappers.html (accessed 7 Sep 2009).

18. Hughes S. Where have all the role models gone? Today's young women admire style over substance. Daily Mail 2009; 13 Jul: http://www.dailymail.co.uk/femail/article1199225/Where-role-models-gone-Todays-youngwomen-admire-style-substance.html (accessed 7 Sep 2009).

DOI: 10.3399/bjgp09X472737 